\title{
Minration, ethnicity and race relations
}

\author{
Antnony H. Richmond \\ York University (Canada)
}

\section{Migration, ethnicity and race relations}

Although many multi-racial and ethnically pluralistic societies today are not the outcome of contemporary population movements, almost all situations of race and ethnic contact have arisen as a consequence of past migration. Some countries have racial and ethnic minorities that are indigenous and have retained distinctive characteristics over many generations. However, the increasing scale and ease of air transportation today is facilitating large-scale movements of population, both legal and illegal, between countries with very different cultural traditions and levels of economic and social development. Before considering migration in the context of race and ethnic relations, it is necessary to examine some general aspects of the sociology of migration in industrial and post-industrial societies. This will involve a multivariate approach in the context of general systems theory. The distinctive features of such an approach are:

(1) recognition that societies are complex socio-economic and sociocultural systems in constant process of adaptation to internal and external sources of change, in which factors conducive to order and to conflict co-exist;

(2) recognition that adaptation is achieved through positive and negative information feedback in which members of a society, individually and collectively, leam from experience and modify behaviour accordingly or, failing this, persist in behaviour patterns entrenched in past experience, which lead to non-adaptive responses and unproductive conflict (Buckley, 1967).

\section{Sociology of migration}

From a sociological point of view, the distinction between international and internal migration is somewhat artificial. Factors which encourage or inhibit 
geographic mobility frequently transcend the artificial boundaries of nationstates. However, the latter have the power legitimately to impose restrictions on population movement across borders through political and administrative controls on immigration and emigration. Through the issue of residence and work permits, some countries, such as South Africa, exercise control over internal migration in the same way, but this is less frequent than the control over international movements. Therefore, internal migration tends to be more responsive to the economic and social conditions that encourage migration. Nevertheless, there is an increasing tendency for employers to tap sources of unskilled and skilled labour outside their own country and for the informal social networks that encourage migration to transcend national boundaries.

Sociological research in various countries has demonstrated the relationship between the flow of migrants and factors such as distance, per capitc differences in income levels, rates of unemployment, intervening opportunities and competing migrants (Jansen, 1970). Various attempts have also been made to generate a typology of migration. One such typology distinguishes between migration in primitive and more advanced societies and further differentiates types of migration by the factors impelling them. Migration may be further classified according to its consequences. Certain types of migration may be innovating and others conservative with regard to the maintenance of culture patterns and social systems (Petersen, 1958).

It has been conventional to distinguish between voluntary and involuntary migration and to assess the relative importance of 'push' and 'pull' factors in describing and explaining particular migrations. Implicit in most sociological studies of migration is the assumption that human beings are normally sedentary and require some inducement to move. Societies tend to be represented as closed systems in which inward and outward population movements are sources of instability and disequilibrium. These assumptions are questionable in the light of contemporary conditions in advanced industrial and post-industrial societies. Geographic, occupational and social mobility are functional prerequisites of an advanced society. Large scale movements from rural areas, giving rise to a significant net gain to urban areas, are characteristic of the early stages of industrialization. However, migration in advanced industrial societies tends to take the form of multi-way exchanges of population between urban areas. The net gains and losses as a consequence of these exchanges of population are small compared with the total movement (Jackson, 1969).

As long as there are still substantial economic differentials within and between countries, net movements will tend to favour the more highly industrialized areas. However, almost everywhere an exchange or 'circulation' of labour and consequent high return movements of workers and their ' dependents are found. Return migration and an oscillation of people between rural and urban areas, or between more than one urban location of residence, are increasingly characteristic of contemporary migratory movements (Mayer, 1961; Richmond, 1968; Nagata, 1973).

The present state and future prospects for migration in the context of race 
and ethnic relations cannot be considered without reference to world population problems. Three aspects must be considered. Firstly, there is the question of world-population growth and its effects on non-renewable resources. Secondly, the uneven distribution of the world's population at the present time combined with differential rates of natural increase giving rise to a 'population explosion' in certain regions of the world, already relatively overcrowded. Thirdly, the uneven distribution of the world's wealth and productive capacity in which the large majority of the world's population has been falling relatively farther behind the standards of the affluent minorities in Western Europe and North America (Forrester, 1971; Meadows, 1972; Cole, 1973). These factors all generate powerful sources of conflict and pressure to migrate.

Attempts to encourage fertility control in developing countries have already been interpreted by some militant Third World representatives as a further attempt to maintain them in a state of subjugation. Even if the gloomy neo-Malthusian predictions of those forecasting a total collapse of the world's economic system are unjustified, there is little doubt that a combination of more effective fertility controls and resource conservation will be essential in the future. Meanwhile, the differential distribution of population and of wealth will continue to provide a dynamic force encouraging migration from the less developed to the more advanced countries of the world. As the latter move into the post-industrial phase of economic development, their own labour requirements will decline. Technological innovations that enable automation and computerization to replace human beings in previously labour intensive occupations will diminish the demand for immigrants, even in those countries that have been traditional reception areas, such as the United States, Canada and Australia. Political and administrative controls over immigration will probably get tighter and advanced societies will endeavour to relate immigration policies to their own population and economic goals (Böhning, 1972; Klaasen and Drew, 1973). The latter are likely to move increasingly toward the maintenance of equilibrium rather than growth.

Within and between countries in the post-industrial phases of economic development, there will continue to be a substantial flow of migration of the exchange type, i.e., a multi-way movement of population between urban and metropolitan centres in which the net gains and losses are a small proportion of the total movement. Such exchange migration is generally made up of relatively well educated people with similar demographic and other characteristics who simply replace each other in the respective economic and social systems. When these societies achieve stable equilibrium and cease to be governed by the belief that economic growth is essential, the need for net additions to population by migration will decline. At the present time, metropolitan centres continue to grow rapidly as a result of both external and internal migration, generating a dynamic interdependence between urban centres and their respective hinterlands (Forrester, 1969; Warmeryd, 1968).

Some immigration from Third World countries may be perceived as 
necessary by advanced countries for diplomatic reasons and as a 'safety valve' in the face of population pressures in developing countries. However, even large scale movements from the Third World to advanced societies would not resolve the major crises that are now imminent in the face of exponential rates of population growth and resources consumption. There is an urgent need for a radical redirection of scientific research applied to problems of food production, the discovery of new energy sources, and to finding ways of limiting pollution and ecological damage, etc., while, at the same time, permitting large scale investment in manufacturing and other industries that will directly benefit the inhabitants of the developing countries.

The distribution of wealth and income within advanced societies will continue to be debatable questions of political and social policy. However, if these countries can reach a stable equilibrium in terms of their own economic growth, this will provide the necessary breathing space during which the less developed countries can begin to catch up. It will be necessary for them to go through at least some of the stages in the processes of urbanization and industrialization previously experienced in Western Euorpe and North America. It seems unlikely that these countries will be able to make the 'quantum leap' into a post-industrial, leisure-oriented society without first eliminating the abject poverty now characteristic of such a large part of the world's population. The greatest challenge facing social scientists in the late 1970s is how the goals of zero population growth and economic equilibrium can be made compatible with improved material standards for those now living near the poverty line and with a more equitable distribution of the world's wealth and resources in the future.

The role of international migration in this process will be a complex one. Among the highest priorities should be a reversal of the 'brain drain' so that the professional, scientific and managerial skills that have served to enhance the wealth of the Western world can be used to benefit the Third World in the future. One of the most valuable contributions to the improvement of race and ethnic relations throughout the world would be the voluntary rotation of highly skilled personnel from Western countries in the service of the Third World countries contributing to their development and welfare. This would be a reversal of present trends in which migrant labour from developing countries is exploited in the interests of those already more affluent (Rex, 1973).

Factors influencing population growth and movement may be represented in terms of a systems model, as illustrated in Figure 1. For any country or region, population growth (or decline) depends upon the combined effects of natural increase and net migration. Rates of fertility and mortality are partly determined by the sex and age composition of the population in question, but are also closely related to the level of education and the quality of health and other social services available. Immigration is also influenced by the age structure, the availability of services and by the per capite level of income, relative to that of other countries or regions. It is also affected by the level of unemployment and, above all, by the demand for labour generated by industrial activity and growth. The latter is generally mediated through 


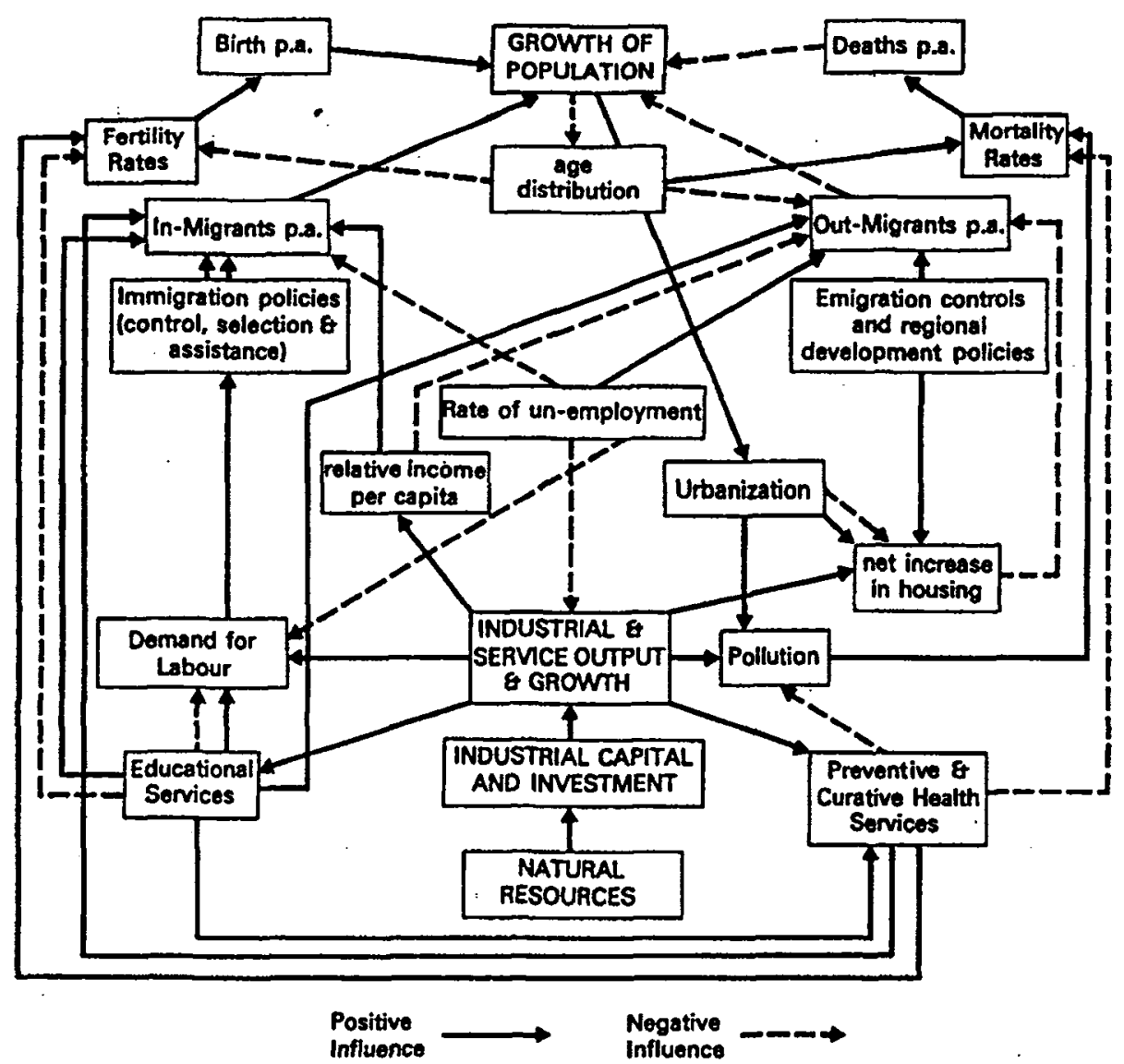

Figure 1. - A systems model of population dynamics and migration.

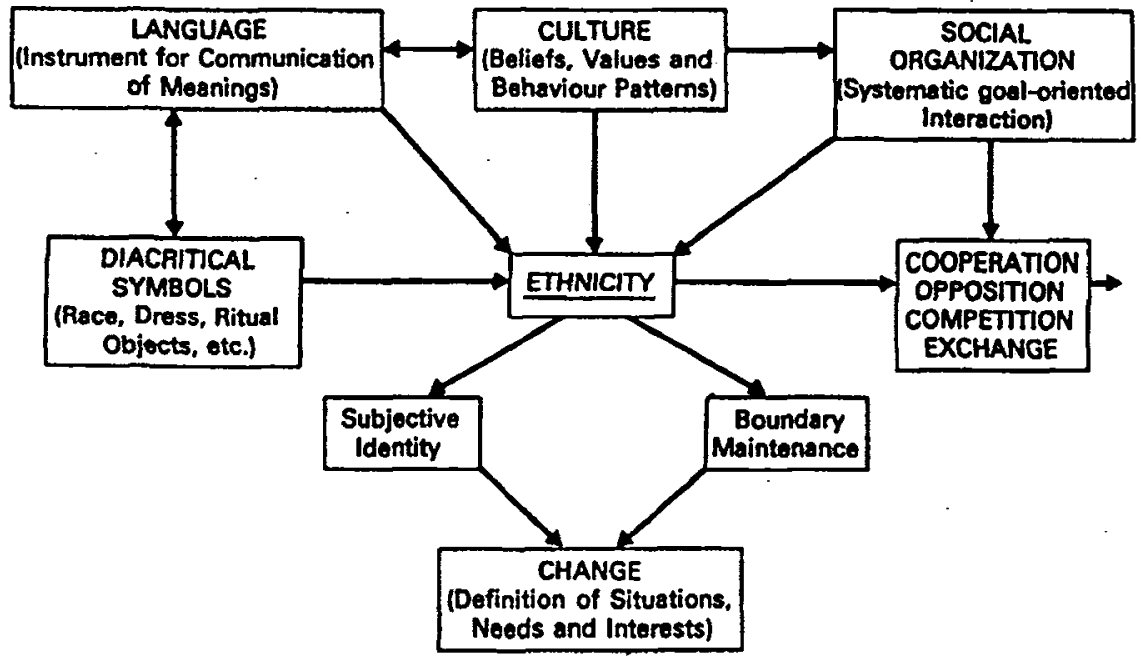

Figure 2. - The components of ethnicity. 
ofticial immigration policies which may positively encourage or discourage immigration from selected countries, or of persons with certain skills or qualifications. Immigration may also be assisted, in some cases, by financial aid with fares, where long distances are involved. Emigration is generally subject to less direct control but may be discouraged by welfare and regional development programmes designed to prevent loss of population from certain areas. The availability of housing may be a factor encouraging or discouraging migration. An important feedback loop to note is that linking education with out-migration. Higher education increases the propensity to migrate and the distance moved. It follows that in advanced countries with a high level of education, there is a substantial amount of internal and external migration, much of it taking the form of a replacement population for those moving out of a given locality. Education also reduces the demand for labour, due to the adoption of automation and other less labour intensive methods of production. However, it may create a demand for certain types of unskilled and service employment that better educated people are reluctant to undertake.

Minorities, ethricity and pluralism

It is evident from the above consideration of population movements that there can be no simple relation between migration and patterns of ethnic relations. The concept of ethnicity is itself a complex one. Although. the ethric characteristics of an individual are generally regarded as ascribed, they are by no means static or unchanging attributes. Ethnicity is a dynamic concept which is responsive to changing situations. This is particularly evident when there is culture contact through migration. Ethnic boundaries persist despite the fact that some people move from one ethnic group to another and undergo a change of ethnic identity (Barth, 1969). The relationship between the various components of ethnicity are illustrated in Figure 2. Although ethnicity involves the sharing of cultural beliefs, values and behaviour patterns, these may be the result of contact and interaction rather than the ascribed basis of definition. The relationship between language and culture is important in this respect. A common language is one basis on which ethnic identity may be maintained and is an instrument for the transmission of culture. It may also be one of the diacritical symbols that facilitate boundary maintenance between ethnic groups. When ethnicity is more than a mere categorization, it also involves elements of social organization which in turn give rise to systematic interaction with other groups on a basis of social and economic exchange, cooperation, opposition and competition.

Multi-ethnic societies that have arisen as a consequence of past or recent migration may exhibit varying degrees of conflict and cohesion. Conflict may arise out of competition for scarce resources, the differential distribution of power within the society, fundamental opposition of basic value systems and inherent contradictions in the values held and the institutions serving them. Such conflict may coexist with the countervailing forces promoting 
greater order and stability. These may include economic interdependence and exchange relationships emerging in the market context, the emergence of an underlying consensus on basic values that encourage tolerance of diversity, together with the translation of coercive social controls into legitimated authority, accepted by the various ethnic groups concerned (Schermerhorn, 1970).

The representation of a social system, particularly one in which there is migration and ethnic variation, as either a 'conflict' or a 'consensus' model is misleading. These are complementary rather than alternative ways of representing processes of social order and change. Competition for scarce resources only takes place when there is some consensus on the value of the resources in question. The overt expression of many conflicts is constrained by an underlying consensus concerning the appropriate means towards their resolution. They may be institutionalized, as in a parliamentary democracy, or ritualized in various ways. Fundamental conflicts over the distribution of power may not be effectively constrained in this way but lead to a redefinition of the social order in terms of alternative sets of values. When power shifts from one group to another, various means are adopted to generate a new consensus. These involve a manipulation of the 'master symbols of legitimation' until new forms of authority are firmly established (Mills, 1959). Opposition and dissent are never entirely eliminated and remain a potent source of further change. The relationships between power, conflict, consensus and change are illustrated in Figure 3. A specific application of this paradigm to a situation of migration and race relations may be found in my own study of Bristol, England (Richmond, 1973).

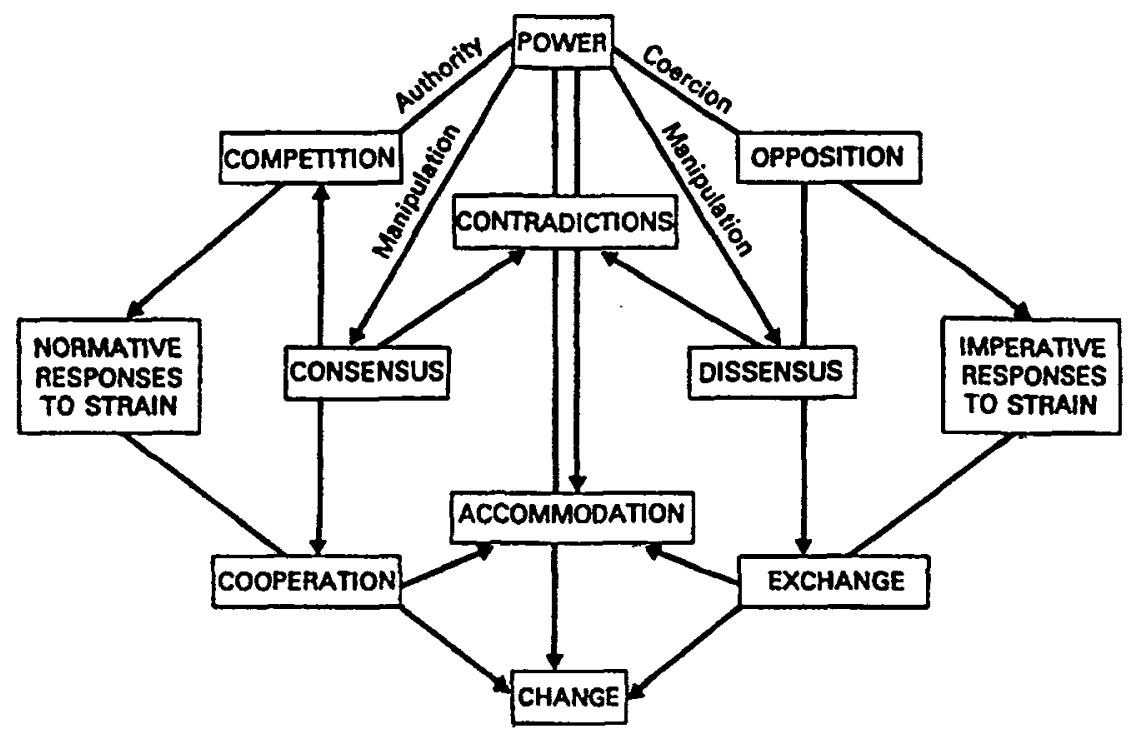

Figure 3. - Model of conflict, order and change. 
Despite ideologies that favour conformity to the dominant elite or absorption into a common 'melting pot', immigration rarely gives rise to the complete assimilation of minority groups. Even after several generations, immigrants and their descendants tend to retain some distinctive attributes that define their ethnic identities and place constraints upon occupational achievement and social mobility. This gives rise to systems of ethnic stratification and to occupational specialization by ethnicity within the economic system. Evidence suggests that reward disparity and social segregation, when combined with a differential distribution of power, lead to less frequent overt conflict but, when such conflict manifests itself, it tends to be more intense and violent. When immigrant groups and other ethnic minorities are more closely integrated and there is less differentiation of power and status, conflict may be more frequent but is less likely to erupt violently (Newman 1973).

Some advanced societies that have admitted significant numbers of immigrants from countries with different linguistic and cultural traditions have sifted the ideological emphases from complete assimilation to a more realistic acceptance of some degree of pluralistic integration (Borrie, 1959; Richmond 1967; Roberts, 1972). Nevertheless, there is considerable variation from one country to another in the extent to which immigrants are assisted in the initial stages of adaptation to the receiving society and in the degree to which they are permitted or encouraged to retain distinctive ethnic identities and to retain these in the second and subsequent generations. The study of, immigrant adaptation requires a multivariate approach (Brody, 1970). The major components of a multivariate model of the immigrant adaptation process are outlined in Figure 4.

Situational factors in the receiving society will have an important bearing upon the subsequent modes of adaptation of immigrants. Demographic factors include the sex and age structure of the receiving country, including dependency ratios, rates of growth of the labour force, etc. The stage of urbanization and industrialization will have an important bearing upon the capacity to absorb immigrants and the specific occupational and other skills in demand. Government policies with regard to the admission of immigrants, including the total size of the immigrant movement and its composition in terms of place of origin and qualifications, will reflect both the social structural determinants of geographic and social mobility, together with the attitudes and values of the dominant groups within that society. Another important influence will be the degree of ethnic pluralism and social stratification already prevailing and the ways in which immigration may modify these.

Interacting with the situational determinants will be the premigration characteristics of the immigrants themselves. Among these the education, technical training and prior experience of urban life exhibited by the immigrants will be important determinants of subsequent patterns of adaptive behaviour. The demographic characteristics of immigrants will be significant, particularly the degree of similarity or dissimilarity to the receiving society. The age, sex and ethnic characteristics of the immigrants may reinforce those 


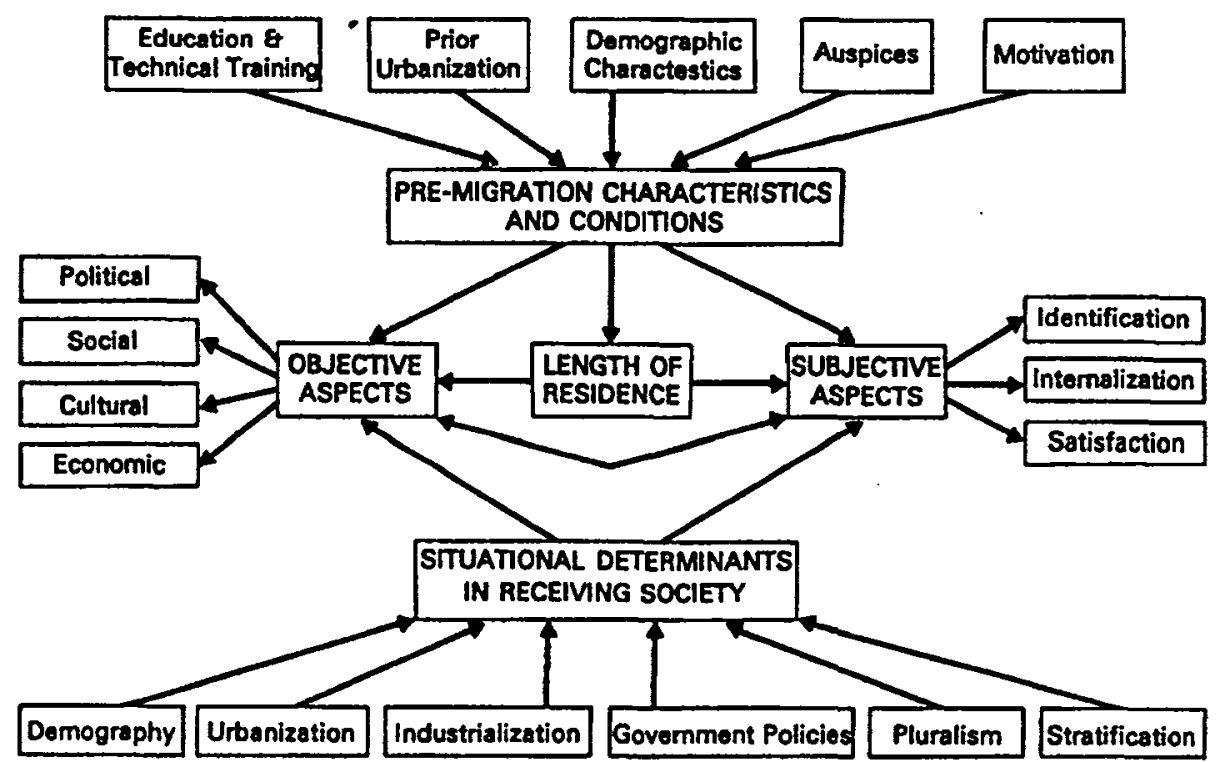

Figure 4. - Multivariate model of the immigrant adaptation process.

of the receiving society or modify them in ways which may shift the balance of numbers and power. Auspices of immigration are also important in determining subsequent modes of adaptation. Immigrants may be sponsored by close relatives, be relocated as part of a refugee movement or respond to a variety of inducements offered by governments and travel agencies who encourage international migration. The original intention and motivation of the migrants will also influence the probability of permanent settlement and the propensity to maintain previous cultural attachments or to adopt the language and cultural characteristics of the dominant groups in the receiving society.

The major intervening variable in the process of adaptation is length of residence in the receiving society. The adaptation process itself can be divided into the overt behavioural or objective aspects and the subjective or sociopsychological aspects. The objective aspects include economic integration, acculturation, social integration at the primary and secondary levels, together with integration into the political system. The latter includes the eventual acquisition of citizenship and participation in the political life of the receiving society through the exercise of the franchise, etc. On the subjective side, adaptation involves achieving some degree of relative gratification with life in the new country, the internalization of new beliefs and values, together with a gradual identification with the new country. The latter will include the gradual modification of ethnic identity and varying degrees of commitment to the country of adoption. In addition to length of residence, the level of 
education of the immigrant population and a culturally or psychologically determined predisposition to maintain ethnic social distance appeared to be the major determinants of the specific types of accommodation to the experience of migration, giving rise to a variety of different modes of immigrant adaptation (Goldlust and Richmond, 1973).

At the risk of some oversimplification, contemporary international migrants may be placed in one of the following categories:

(1) Assimilating permanent settlers: Immigrants in this category already have or quickly acquire linguistic and cultural characteristics similar to that of the receiving society and are absorbed into the economic and social systems with minimal status dislocation and without generating ethnic stratification. Examples include movements between the United States and Canada and between 'white' members of the British Commonwealth.

(2) Pluralistically integrated permanent settlers: Immigrants in this category are readily distinguishable from the majority or dominant group in the receiving society and continue to retain many of the linguistic and cultural characteristics brought with them from the former country. Their absorption often gives rise to a system of ethnic stratification with varying degrees of occupational and social mobility in the first and subsequent generations. Examples include many countries in South East Asia, together with some European and Asian communities in North America.

(3) Quasi-migrants: This category includes all those who established temporary residence in another country, frequently leaving dependents at home, and who rotate or oscillate between one or more countries. They include many 'guest workers' in European countries, together with students and others who have working vacations', and those whose motive for migration is travel for its own sake.

(4) Transilient mignants: This category is similar to that of the quasimigrant in that they do not establish permanent residence. However, this is more often a family migration and is characteristic of those with high managerial, professional or technical qualifications that are in demand in various countries. They include the employees of multi-national corporations, together with many doctors, nurses, teachers, scientists, etc. who regard international migration as a concomitant of career mobility.

(5) Permanent repatriates: These include all migrants who have lived or worked abroad and have now returned to the country of origin for permanent resettlement. Re-integration into the country of origin frequently involves similar processes of adaptation to those experienced in the original migration. This category includes those 'returnees' who were disappointed in their original expectations, or were unable to adapt to the new country, together with others who 
were successful and fully satisfied with their experience of migration. The latter may include some who retire to the country of birth.

\section{Race and racism}

The migration of highly visible populations physically distinguishable from those of the receiving society is a special case because of the racist attitudes that prevail in many societies. The concept of 'race' is still a highly controversial one. Despite a near consensus among biologists and social scientists concerning the inappropriateness of dividing human populations into discrete categories based on physical or other attributes, racism persists as an influential ideology in many societies (UNESCO, 1968; Van den Berghe, 1967). The fallacy that human beings can be allocated to specific racial groups on the basis of superficial characteristics such as skin colour is further compounded by the widespread belief in the inherent superiority and inferiority of the groups in question. Although differential opportunities for inter-marriage have given rise to distinctive gene-pools, these correspond only very roughly to conventionally defined racial differences. Social scientists generally agree that, in practice, 'races' are social categories in which certain physical characteristics have been arbitrarily selected and given symbolic importance in the allocation of human beings to social roles (Banton, 1967). The ideologies associated with racism provide elaborate theological, biological and sometimes sociological rationalizations for the stigmatic view of certain racial characteristics. At the same time, these ideologies endeavour to legitimate institutionalized forms of racialism which may persist over several generations forcibly segregating populations and differentially allocating them within the educational and occupational opportunity structure of the society (Shibutani and Kwan, 1965; Rex, 1970).

In examining the problems created by racism, two separate and distinct issues arise. Firstly, what are the conditions under which racist attitudes become endemic and widespread in a particular culture and racialist policies and practices institutionalized? Secondly, what are the factors which account for the differential propensity of certain categories of the population to internalize such attitudes and actively endorse racism rather than reject and oppose racism? The first question involves an examination of the historical context in which racism emerges and the particular structural and situational conditions that are conducive to its expression. Although earlier examples of incipient racism may be traced, it seems that its most serious manifestations emerged with the mass migration of the eighteenth and nineteenth centuries, which coincided with the imperialist policies of many western European countries. The colonial expansion of these countries involved the near extermination of many indigenous populations in the New World. In territories deemed suitable for European settlement, there followed the coercive segregation of those who survived, the importation of slave and indentured labour, and the development of ideologies that justified the perpetuation of the subordination and segregation of the non-European 
members of the population (Williams, 1966). In parts of Africa and Asia not deemed suitable for permanent European settlement, political domination was combined with the exploitation of labour and natural resources to provide the raw materials for the rapidly expanding industrial economies of Europe. The elaborate religious and pseudo-scientific theories that were developed to explain and justify.these systems of exploitation have persisted to the present day and are still widely held, despite their discreditation by responsible authorities. They continue to provide a convenient mythology in support of policies that discriminate against racial minorities and immigrant groups in many countries (Mason, 1971).

A recent development has been the adoption of racist counter-ideologies by subordinated minorities in advanced countries and by some Third World countries pursuing discriminatory policies against national, ethnic and racial minorities within their borders. Notwithstanding the lack of any scientific justification for treating human beings as if they, could be placed in clearly defined racial groups, it is not surprising that concepts such as 'Black Power' and 'Red Power' should have a powerful appeal to underprivileged and exploited minorities (Blauner, 1972). Such ideologies serve to redress the stigmatic nature of former racial and ethnic definitions of identity. In the case of newly independent countries, resentment against racial and cultural minorities who, in many cases, had achieved economic status and political influence under the sponsorship of former imperial powers, generates considerable hostility toward these minorities, in some cases leading to their eventual expulsion (Plender, 1972).

Notwithstanding the widespread nature of racist ideologies or counterideologies and their manipulation by political leaders, they are not uniformly accepted. The evidence from a variety of socio-psychological studies suggests that personality factors, early socialization experience and subsequent feelings of security or insecurity in the performance of social roles may determine the extent of racial prejudice exhibited by particular individuals. Among the factors found to be associated with a greater propensity to express racial prejudice are authoritarianism, anomia and alienation, rigidity and intolerance of ambiguity, status insecurity and very marked upward or downward social mobility (Blalock, 1967; Bloom, 1971). Situational determinants include the degree to which racial minorities are perceived as threatening and competing for scarce resources such as eimployment, housing or welfare benefits. Questions of relative rather than absolute status deprivation appear to be important in determining whether racial and ethnic groups engage in confrontation and overt conflict of a violent type. Marginal members of the dominant group may feel themselves threatened by the actual or potential upward mobility of members of the subordinated groups.

Whether a situation of inter-ethnic and inter-racial conflict or tension gives rise to widespread violence of a collective nature, including riots, rebellions and overt revolutionary actívity, will depend upon a complex inter-play between many forces. Some of these are conducive to violence and others constrain such outward expressions of underlying conflict. The inter-relation 
between these factors is illustrated in multivariate model form in Figure 5. Racist and chauvinistic ideologies maintained by dominant elites and superordinate strata in society will tend to promote violence, particularly if they are accompanied by opposing counter-ideologies of the minority groups. However, the impact of these ideologies will be mediated through the mass media which may play down, or som tintis inflame, the attitudes of the opposing groups. The ideological factors will be further modified by the selective response to them by the populations concerned which, in turn, may depend upon a variety of socio-psychological and personality determinants. Actual level of material, social and cultural differentiation may be less important than perceived levels and consequent feelings of relative rather than absolute deprivation. In this connection, the distinction between individual and fraternal, or in this context specifically interethnic, deprivation is likely to be important. Evidence suggests that violent rebellion is particularly likely to occur in situations where a minority group has experienced a sense of relative deprivation of economic, social and political status, compared with other groups adopted as reference models in that society (Gurr, 1970).

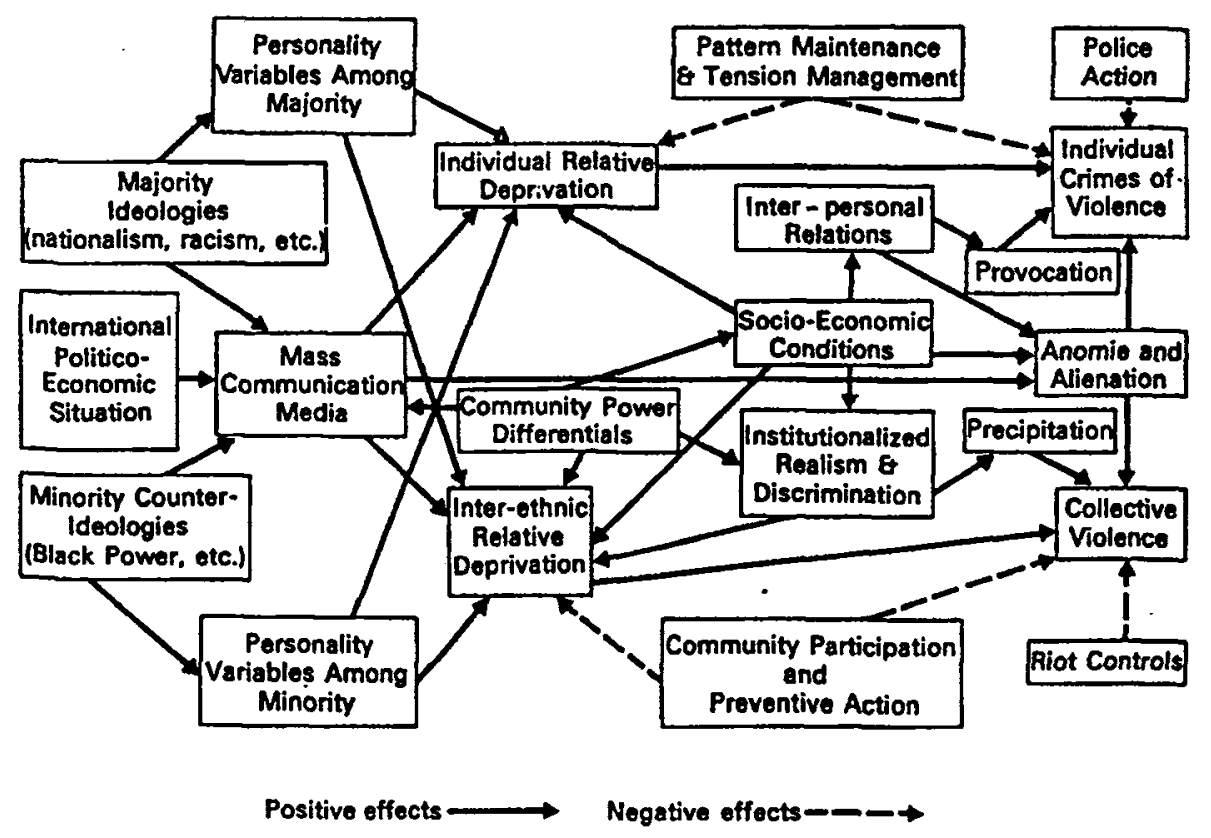

Figure 5. - Factors associated with individual and collective violence in race and ethnic situations: a multivariate model.

Needless to say, the differential distribution of power between dominant and subordinate ethnic and racial groups will be contributory, although violence often breaks out precisely when the balance of power is beginning to shift slightly more in favour of the 'under-dog'. Institutionalized forms of racism and discrimination will also be conducive to violence, although the 
monolithic use of coercive power, such as that of the police and military, may temporarily inhibit or quell violence, as will the para-military techniques of riot control that have been developed in recent years (Feagin, 1973). This is because the 'cost' of any violent outbursts may be seen as too great. However, such coercive measures do nothing to remove the underlying causes of conflict and tension and may simply lead to a displacement of energy into other forms of deviant behaviour, individual crimes of violence, homicide, suicide and other symptoms of generalized alienation on the part of minorities. More effective social controls include efforts to involve minority groups in programmes of local community action designed to ameliorate social conditions and achieve constructive citizen participation in civic action and local politics.

\section{Neo-colonialism}

Reference has been made to the imperial expansion of Western European powers in the nineteenth century and the situations of political subordination and racial stratification that were created. The aftermath of these colonial regimes is still to be observed in the patterns of economic dependency and migration between the less developed and the more industrially advanced regions of the world. A classical situation of 'colonialism' exists when the population of a given territory is subject to invasion and external control using coercive means. The land and resources, both material and human, are exploited for the benefit of the imperial power. In some cases, there may be forced labour and involuntary migration in order to ensure an adequate labour supply for the development of mines, plantations or other economic activities controlled by the colonists. The impact of colonialism frequently has a devastating effect on the culture and way of life of the indigenous population. Selected members of the colonized population may be educated and socialized into the way of life of the dominant group in order to provide a cadre of intellectuals, teachers and administrators who will act as agents of the colonial power maintaining effective political and social control. In due course, these same indigenous elites may form the spearhead of an emergent nationalistic movement which displaces the colonizing power and assumes political authority in the newly independent country (Richmond, 1961; Deutsch, 1953; Wallerstein, 1966).

However, the consequences of colonialism may still be observed in the economic dependency of the Third World countries and in the segregated and subordinated position of racial minorities in Western societies. The latter may encourage proletarian migration from former dependencies in order to supply unskilled labour for industries which are unable to provide wages and working conditions sufficiently attractive for their own workers. Furthermore, the economies of the developing countries of the Third World may remain geared to the supply of raw materials for the more advanced countries. In recent years, the provision of a variety of service functions, particularly tourism, for the more affluent countries is also linked to the former colonial 
status. Under these conditions, the better educated inhabitants of the Third World may be tempted to seek improved opportunities for themselves in the advanced countries, thereby contributing to a 'brain drain' (Adams, 1968).

The attitude of Western societies toward immigration from former colonial dependencies and other less developed areas of the world has been distinctly ambivalent. So long as distance and the costs of international travel restricted the numbers likely to want to migrate, the Western countries were relatively liberal in their interpretation of citizenship and other qualifications for admission. However, since the end of the Second World War, air travel has become increasingly practicable and the credit towards its cost available, albeit at high interest rates. Large scale movements of population from developing countries have been encouraged by travel agents and others perceiving profitable opportunities in this movement. As a consequence, both legal and illegal migration to various countries in Western Europe and North America is now widespread. These are now subject to stricter controls but the complete exclusion of such workers is not perceived as in the interest of the advanced countries. Shortages of labour at all levels of skill from the professional down to the semi-skilled factory and construction worker, together with various manual and service occupations, have been met by immigrant labour from various parts of Africa, Asia, the Caribbean and some less developed areas of Southern Europe. In many cases, the economic costs of this type of immigration has been kept at a minimum by not fully incorporating the immigrant workers into the complex welfare oriented social systems of the receiving society. Such immigrants have frequently not been eligible for the housing, health and other social welfare benefits available to the indigenous populations of advanced societies. In many cases, long residence qualifications or citizenship are prerequisites for such benefits (Rex, 1967; Casties and Kosack, 1973).

The situation of racially and ethnically distinct immigrant minorities in some advanced societies is further aggravated by the discouragement given to permanent residence. The rotation of 'guest workers' in some European countries provides a constant supply of relatively unskilled labour generally separated from their own families and subject to strict control over length of residence, political representation, etc. Such a system may be described as a form of 'external apartheid'. As experienced in the Republic of South Africa, apartheid is a system which enables a small white minority to maintain political and economic control over the Black, Coloured and Asian inhabitants that make up $90 \%$ of the population. This is achieved by legislation that provides a strict control over location of residence, type of employment, political activity and social behaviour of the non-white population. There are also severe penalties for white South Africans who breach laws that restrict social interaction with non-whites, outlaw miscegenation and limit freedom of political organization. One of the features of the system is temporary migration of labour from neighbouring African countries and the Bantustans (which are officially regarded as the legitimate 'home' of the African population) to urban areas, white farms and mining areas controlled by 
national and international corporations. Such a system minimizes the overhead costs that would normally be involved in the provision of permanent family housing, unemployment, sickness and pension rights for a permanent labour force in a modern society (Adam, 1971). There is some resemblance between this system and that operated by some European countries that permit the migration but not the permanent settlement of immigrants from certain countries. The situation leads to the creation of an industrial 'reserve army' susceptible to exploitation by advanced societies (Rex, 1973).

\section{Conclusion: research needs}

There will always be a need for specialized studies that address themseives to fundamental theoretical issues in the social sciences that have implications for migration and inter-ethnic relations. In psychology, there is a need for further work on the motivational factors influencing the propensity to migrate, as well as further research on the dynamics of racial and ethnic prejudice. In sociology, further research is needed on the relation of geographic to occupational and social mobility, as well as on the institutional factors creating and perpetuating systems of racial and ethnic stratification. Social historians have an important contribution to make in studying patterns of migration and their consequences for cultural and social change, together with the genesis and spread of racist ideologies. Geographers and demographers need to develop more sophisticated models of population growth and distribution and to examine their consequences for urbanization, suburbanization and human ecology. In this they will need, also, to draw upon the work of economists concerned with the supply and demand for labour, resource utilization and conservation and the political economy of welfare services in developing and advanced societies. Political scientists should also address themselves to questions of immigration policy and its relation to other aspects of domestic and foreign policy in a comparative framework, together with studies of the public administration of services designed to assist the integration of immigrants or to minimize the possibility of interethnic tension arising from international movements of population.

If specialized studies, from the point of view of particular academic disciplines, are to be of value to planners and administrators contributing, in the long run, to the solution of some of the momentous problems facing mankind in the last quarter of the twentieth century, they must be brought together within the framework of a general systems approach. Only in this way will the practical and operational implications be fully understood. In this context, the development of systems models and the computer simulation of economic, demographic and social behaviour has great potential application (McMillan and Gonzalez, 1973). At the same time, the fundamental values underlying political and social policies must be fully explicated and incorporated into the analyses undertaken by social scientists. As Sir Geoffrey Vickers has pointed out, "value questions tend to be masked beneath the vast ramifications of our instrumental judgments, judgments of 
how best to achieve some already agreed. end . . . choices based on major judgments of value tend to be masked behind the frequent threats latent in the instability of our system. Too often, we can justify what we do by some manifest disaster that will otherwise overtake us' (Vickers, 1970). Our task for the future should be to find ways of anticipating much sooner the potential disasters and finding ways of developing constructive policies that will fulfil our positive goals rather than merely avoid our negative ones.

\section{Notes}

-This paper was originally presented to a seminar on international migration held in Buenos Aires during March 1974 and an earlier version was published in the conference proceedings, International Migration, edited by George Tapinos, Paris, CICRED, 1974.

\section{References}

ADAM, H. 1971. Modernizing Racial Domination. Berkeley, University of California Press.

ADAMS, S. Walter 1968 The Brain Drain. New York, Macmillan.

BANTON, Michael 1967 Rece Relations. London, Tavistock.

BARTH, Frederik 1969 Ethnic Groups and Boundaries. Boston, Little Brown.

BLALOCK, H. M. Jr. 1967 Toward a Theory of Minority-Group Relations. New York, Wiley.

BLAUNER, Robert 1972 Racial Oppression in America. New York, Harper \& Row. BLOOM, Leonard 1971 Social Psychology of Race Relations. London, Allen \& Unwin. BOHNING, W. R. 1972 The Migration of Workers in the United Kingdom and the European Community. London, Oxford University Press.

BORRIE, W. D. 1959 The Cultural Integration of Immigrants. Paris, U.N.E.S.C.O.

BRODY, E. B. 1970 Beheviour in New Environments. New York, Sage.

BUCKLEY, Walter 1957 Sociology and Modern Systems Theory. New Jersey, Prentice-Hall.

CASTLES, Stephen \& KOSACK, Godula 1973 Immigront Workers and Closs Structure in Western Europe. London, Oxford University Press.

COLE, H. S. D., FREEMAN, C. et al. 1973 Thinking About the Future: A Citique of the Limits to Growth. London, Chat to \& Windus.

DEUTSCH, K. W. 1953 Nationalism and Social Communication. New York, Wiley. FEAGIN, 1973 Ghetto Revolts: The Politics of Violence in American Cities. New York, Macmillan.

FORRESTER, J. W. 1969 Urban Dynamics. Cambridge, M.I.T. Press.

1971 World Dynamics. Cambridge, Wright Allen Press.

GOLDLUST, John 'A Multivariate Model of Immigrant Adaptation', Paper presented at the Conference on 'Policy and Research on Migration: Canadian and World Perspectives', otganized by the International Sociological Association, Research Committec on Migration, University of Waterloo, Ontario, October.

GURR, T. R. 1970 Why Men Rebel. New Jersey, Princeton University Press.

JACKSON, J. A. 1969 Sociological Studies II: Migration. Cambridge, Cambridge University Press.

KLAASEN, L. H. \&.DREW, E. P. 1973 Migration Policy in Europe: A Comparative Study. Lexington, D. C. Heath.

MASON, Philip 1971 Patterns of Dominance. London, Oxford University Press.

MAYER, P. 1961 Townsmen or Tribesmen: Urbanization in a Divided Society. London, Oxford University Press.

McMILLAN, C. \& GONZALEZ, R. F. 1973 Systems Analysis: A Computer Approach to Decision Models. Ininois, Irwin. 
MEADOWS, D. H., MEADOWS, D. L., et al. 1972 The Limits to Growth. New York, Universe Books.

MILLS, C. W. 1959 The Sociological Imagination. New York, Oxford University Press. NAGATA, Judith 1973 'Urban Interlude: Some Aspects of Internal Malay Migration in West Malaysia', Paper presented at the Conference on 'Policy and Research on Migration: Canadian and World Perspectives', organized by the International Sociological Association, Research Committec on Migration, at the University of Waterloo, Ontario, October.

NEWMAN, W. M. 1973 American Pluralism: A Study of Minority Groups and Social Theory. New York, Harper \& Row.

PETERSEN, William 1958 'A General Typology of Migration'. American Sociological Review, 23: 3, pp. 255-56.

PLENDER, Richard 1972 'The Expulsion of Asians from Uganda: Legal Aspects', New Community, Volume 1, Number 5, pp. 420-427.

REX, John \& MOORE, Robert 1967 Race, Community and Conflict. London, Oxford University Press.

REX, John 1970 Race Relations in Sociological Theory. London, Weidenfeld \& Nicholson. 1973 Race, Colonialism and the City. London, Routledge \& Kegan Paul.

RICHMOND, Anthony H. 1961 The Colour Problem: A Study of Racial Relations (Rev. Ed.). Harmondsworth Penguin Books.

RICHMOND, Anthony H. 1967 Post-War Immigrants in Canada. Toronto, University of Toronto Press.

1968 'Immigration and Pluralism in Canada'. The Intemational Migration Review, Vólume 4, Number 1, pp. 5-24.

1973 Migration and Race Relations in an English City. London, Oxford University Press.

ROBERTS, Hew 1972 Australia's Immigration Policy. Nedlands, University of Western Australia Press.

SCHERMERHORN, R. A. 1970 Comparative Ethnic Relations: A Fromework for Theory and Research. New York, Random House.

SHIBUTANI, T. \& KWAN, K. M. 1965 Ethnic Stratification: A Comparative Approach. New York, Macmillan.

U.N.E.S.C.O. 1968 Four Statements on the Race Questions. Paris, U.N.E.S.C.O.

VAN DEN BERGHE, Pierre L. 1967 Race and Racism: Comparative Perspectives. New York, Wiley.

VICKERS, Geoffrey 1970 Value Systems and Social Process. Harmondsworth, Penguin Books.

WALLERSTEIN, I. 1966 Social Change: The Colonial Situation. New York, Wiley. WARMERYD, Olaf 1968 Inter-Dependence in Urban Systems. Gotenburg, Regionkonsult Aktiebolog.

WILLIAMS, Eric 1966 Copitalism and Slavery. Chapel Hill, University of North Carolina Press. 